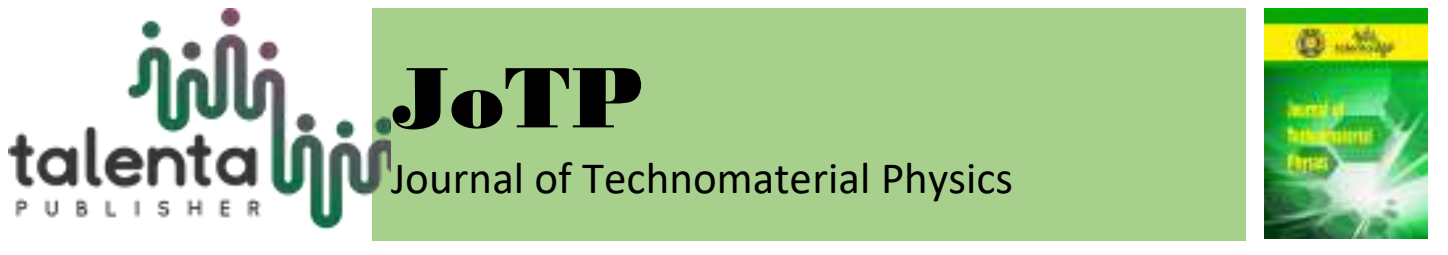

\title{
Carbon Electrodes from Corn Stalk Core for Supercapacitor Application
}

\author{
Rita Juliani', Erman Taer', Miftah 'ainul Mardiah', Rakhmawati Farma' and \\ Awitdrus ${ }^{5}$
}

1,2,3,4,5 Department of Physics, Faculty of Mathematics and Natural Science, Universitas Riau, Pekanbaru 28290, Riau, Indonesia.

\begin{abstract}
The natural pore structure of corn stalk core potentially contributes as a basic material for activated carbon. The activated carbon from a combination of chemical and physical activation is presented for capacitive energy storage. The chemical activation was carried out using $0.4 \mathrm{M} \mathrm{KOH}$ followed by pyrolysis process up to $600^{\circ} \mathrm{C}$ in an $\mathrm{N}_{2}$ atmosphere. The physical activation was conducted at various temperatures such as $600^{\circ} \mathrm{C}$, $700^{\circ} \mathrm{C}$, and $800^{\circ} \mathrm{C}$ with a $\mathrm{CO}_{2}$ gas flow rate of $10 \mathrm{~mL} / \mathrm{min}$. Supercapacitor cells were made from carbon electrodes of corn stalk core, $316 \mathrm{~L}$ stainless steel as the current collector, duck eggshell as the separator, and $1 \mathrm{M} \mathrm{H}_{2} \mathrm{SO}_{4}$ as the electrolyte solution. The physical properties of carbon electrodes were characterized by identifying the density, surface morphology and chemical structure of carbon. The density value was obtained based on the mass, thickness, and diameter of the carbon electrode. The lowest density was found at the activation temperature of $700^{\circ} \mathrm{C}$ which has the potential to produce the best performance in supercapacitor cells. SEM was used to characterize the surface morphology. The activation temperature of $700^{\circ} \mathrm{C}$ showed the formation of irregular structures and provided large pores for the diffusion of electrolyte ions into the carbon matrix. The FTIR characterization was used to determine the carbon chain elements which formed double layers in supercapacitor cells. The electrochemical properties of supercapacitor cells were tested using cyclic voltammetry. Specific capacitances at the activation temperature of $600^{\circ} \mathrm{C}, 700^{\circ} \mathrm{C}$, and $800^{\circ} \mathrm{C}$ were $90 \mathrm{Fg}-1,108.92 \mathrm{Fg}-1$, and $44.875 \mathrm{Fg}-1$, respectively. These results showed that the activation temperature of $700^{\circ} \mathrm{C}$ was the best temperature in the preparation of supercapacitor electrodes from corn stalk core as the biomass material.
\end{abstract}

Keywords: Cornstalk core, Activation temperature, Physical properties, Supercapacitor, Specific capacitance.

Received [28 November 2018] | Revised [25 January 2019] | Accepted [28 February 2019]

\section{Introduction}

Supercapacitors are renewable energy which has high power density and long life-cycle and capable of storing greater electrical energy than conventional batteries and capacitors [1-7]. Based on the storage mechanism, supercapacitors are divided into two types, namely electrochemical double-layer capacitors (EDLC) and pseudo-capacitors. EDLC works at the

\footnotetext{
*Corresponding author at:Bina Widya Km 12.5 Simpang Baru, Pekanbaru 28293, Riau, Indonesia

E-mail address: awitdrus@lecturer.unri.ac.id
} 
interface of electrodes and electrolytes, produces electrostatic attraction for accumulated load charge and discharge on double layer [8], while pseudo-capacitors originate from redox reactions in the electrodes [9].

Conductive polymers and metal oxides can be used as electrode materials. Both have a high surface area and specific capacitance, but poor conductivity and stability [10]. Activated carbon is widely used as a supercapacitor electrode material because of several reasons, such as good physical and electrochemical properties, widely available, low prices, and easier preparation methods [11]. One of the activated carbon materials is biomass waste. In addition to the increasingly limited reserves of fossil fuels, the selection of biomass is beneficial because its preparation is easy, inexpensive, and potentially provides porous carbon with good electrochemical capacitive performance.

Corn Stalk Core (CSC) is immensely good to be used as an electrode material of activated carbon because it contains high lignocellulose. CSC also has a porous foam-like texture. The natural porous texture has the potential to provide carbon with a large surface for electron transfer and short way for ion diffusion in the carbon matrix. Several studies have been conducted on the utilization of corn biomass waste as activated carbon materials, such as corn cobs [12], corn husk [13], and corn leaves [14].

The preparation of activated carbon electrodes also has an important role in converting cellulose into activated carbon. The preparation process of activated carbon consists of two stages: (1) chemical activation using $\mathrm{KOH}$ as an activating agent followed by pyrolysis process up to a temperature of $600^{\circ} \mathrm{C}$; and (2) physical activation by flowing $\mathrm{CO}_{2}$ oxidizing gas. The selection of $\mathrm{CO}_{2}$ as an activating agent is suggested because it is more economical. Furthermore, the reaction that occurs is an endothermic reaction, so it would be easier to control, cleaner, and better used on a laboratory scale. The activation temperature influences the formation of pore structures of the activated carbon produced. Therefore, this study focused on the effect of different activation temperatures.

\section{Materials and Methods}

The initial step of the research was preparing the basic materials of activated carbon electrodes. First, corn stalks were stripped from the leaves and outer skin. CSC was then cut to a size of $\pm 5 \mathrm{~mm}$ and pre-carbonized to a temperature of $250^{\circ} \mathrm{C}$. The refining process of pre-carbonized CSC used mortar and ball milling for 4 hours followed by sieving process so that the grain size $<100 \mu \mathrm{m}$ was obtained. The chemical activation of the CSC pre-carbonized powder using 0.4 $\mathrm{M} \mathrm{KOH}$ was stirred on the hotplate for 3 hours and neutralized to $\mathrm{pH}$ close to 7 . The powder obtained from the chemical activation was then formed into a pellet using hydraulic hack with a pressure of 8 tons. CSC pellets were pyrolyzed using furnace in an $\mathrm{N}_{2}$ gas environment up to a temperature of $600^{\circ} \mathrm{C}$ followed by integrated physical activation using $\mathrm{CO}_{2}$ gas with a gas flow 
rate of 1.5 liters/minute and a temperature rise rate of $10^{\circ} \mathrm{C} /$ minute. Variations in the activation temperatures were $600^{\circ} \mathrm{C}, 700^{\circ} \mathrm{C}$, and $800^{\circ} \mathrm{C}$.

Electrodes were polished using P1200 sandpaper up to a thickness of $\pm 0.02 \mathrm{~mm}$ and washed until the $\mathrm{pH}$ of the pellet was close to neutral ( $\mathrm{pH} \sim 7$ ). Fabrication of supercapacitor cells was started by soaking the $\mathrm{CSC}$ carbon electrodes into $1 \mathrm{M} \mathrm{H}_{2} \mathrm{SO}_{4}$ for 48 hours. The materials used in the preparation of supercapacitor cells include supercapacitor bodies made of acrylic, two CSC carbon electrodes, current collectors (316L stainless steel), separators (duck eggshell), and $1 \mathrm{M} \mathrm{H}_{2} \mathrm{SO}_{4}$ as the electrolyte solution. Afterward, the materials were arranged to form a sandwich.

The physical properties of the carbon electrodes tested were density, surface morphology, and the carbon chain structure of activated carbon. Density was obtained from the measurement of mass, diameter, and thickness of carbon electrodes before and after activation. The surface morphology was obtained from electron scanning microscope characterization using the SUPRA S-3400N with 1,000X and 20,000X magnifications. On the other hand, the carbon chain structure of activated carbon was determined with the Fourier-infrared transformation characterization using IRPestige-21 SHIMADZU.

The electrochemical properties were tested by using Physics CV UR Rad-Er 5841 tool controlled by Cyclic Voltammetry (CV) v6 software with a potential width of 0-500 $\mathrm{mV}$ and a scan rate of $1 \mathrm{mVs}^{-1}$. The data were calculated to obtain the specific capacitance of the supercapacitor cells using the equation:

$$
\mathrm{C}_{\mathrm{sp}}=\frac{\left(\mathrm{I}_{\mathrm{c}}-\left(-\mathrm{I}_{\mathrm{d}}\right)\right.}{\mathrm{s} \times \mathrm{m}}
$$

where $C_{s p}$ is specific capacitance (Fg-1), $I_{c}$ is the charge current (A), $I_{d}$ is the discharge current (A), $\mathrm{s}$ is the scan rate $\left(\mathrm{mVs}^{-1}\right)$ and $\mathrm{m}$ is the mass of the activated carbon electrode $(\mathrm{g})$.

\section{Result and Discussion}

\subsection{Physical Properties of Carbon Electrodes}

The electrode density is closely related to the formation of pore structure, particle size, and resistance produced when measuring supercapacitor cells. The formation of pore structures occurs in the activation process. The density data before and after activation are shown in Figure 1. The electrode density values before activation were nearly the same for all temperatures whereas there was a significant density decrease after activation. The decrease in density might be caused by the removal of compounds other than carbon, termination of carbon chains, and the formation of new pores. The highest decrease in density was produced by CSC700. Thus, it can be said that $700^{\circ} \mathrm{C}$ is the optimum temperature in the formation and improvement of the pore structures. A temperature higher than $700^{\circ} \mathrm{C}$ would increase the density. The increase 
occurs because particles that have been formed will be damaged and cover existing pores [15]. The increase in density can reduce the porosity of activated carbon, so the specific capacitance produced decreases [16].

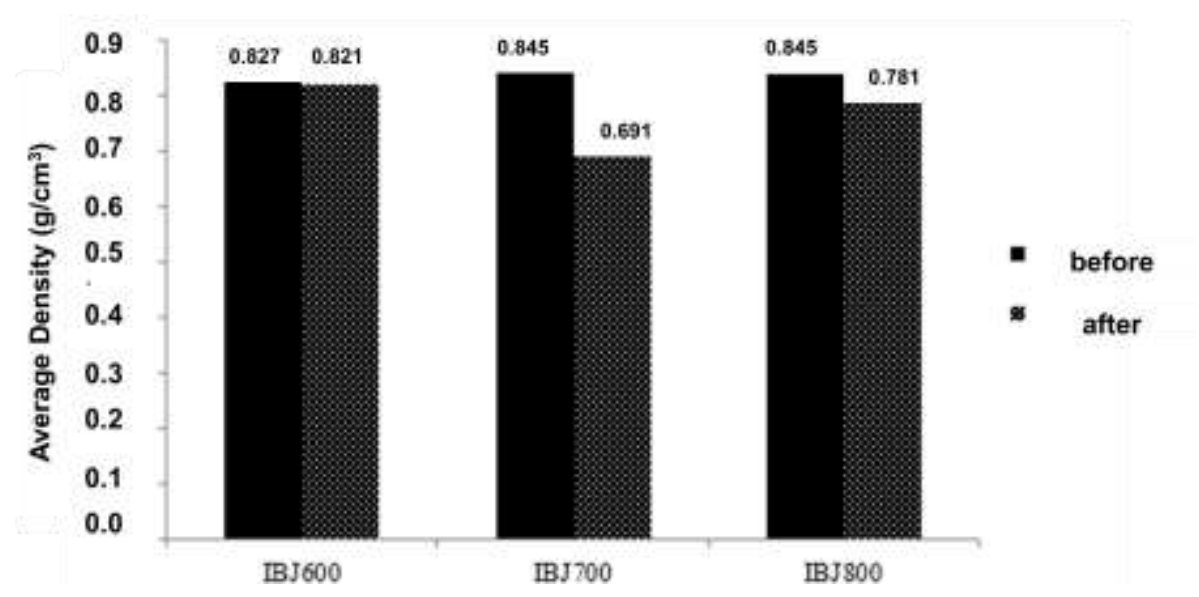

Figure 1. Graph of changes in the average density of CSC carbon electrodes before and after activation.

The morphology and microstructure of CSC700 were characterized using an electron scanning microscope. The morphological and microstructure images of CSC700 are shown in Figure 2 with 1,000X and 20,000X magnifications. The microstructure of CSC700 was composed of particles of various sizes while the surface was formed like a basin. The pore diameter sizes ranged between $0.882 \mu \mathrm{m}$ and $2.316 \mu \mathrm{m}$. The pore functions in facilitating electrolyte ions to penetrate the carbon matrix [17].
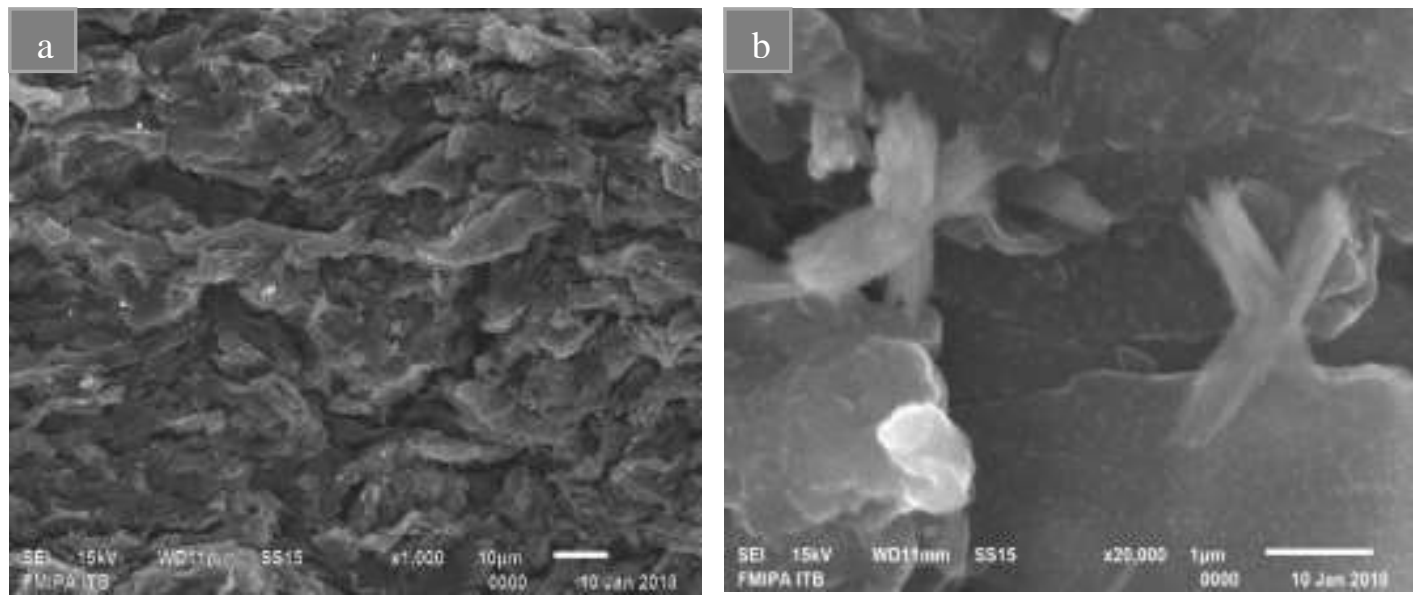

Figure 2. The surface morphology of CSC700 (a) 1,000X magnification; and (b) 20,000X magnification.

The carbon chain structure of CSC700 was analyzed by using Fourier-infrared transformation spectroscopy in the wavenumber range of 400-4000 $\mathrm{cm}^{-1}$. Spectral peaks shown in Figure 3 are the specific characteristics of activated carbon spectrum [18]. There are many O-H functional groups in the wavenumber range of $2900-3600 \mathrm{~cm}^{-1}$. The $\mathrm{C}-\mathrm{H}$ functional group detected 
stretching vibrations at wavenumber $2877 \mathrm{~cm}^{-1}$ and $860 \mathrm{~cm}^{-1}$ [19]. The activation process has also formed stretching vibrations $\mathrm{C}=\mathrm{C}$ at peaks of $2131 \mathrm{~cm}^{-1}$ and $1521 \mathrm{~cm}^{-1}$. The $\mathrm{C}=\mathrm{C}$ aromatic ring is a constituent of the hexagonal structure of activated carbon. Further, there is a C-N functional group at the wavenumber $1311 \mathrm{~cm}^{-1}$ [20]. This $\mathrm{C}-\mathrm{N}$ arises because a reaction occurs between the $\mathrm{N}_{2}$ activating agent and the carbon produced.

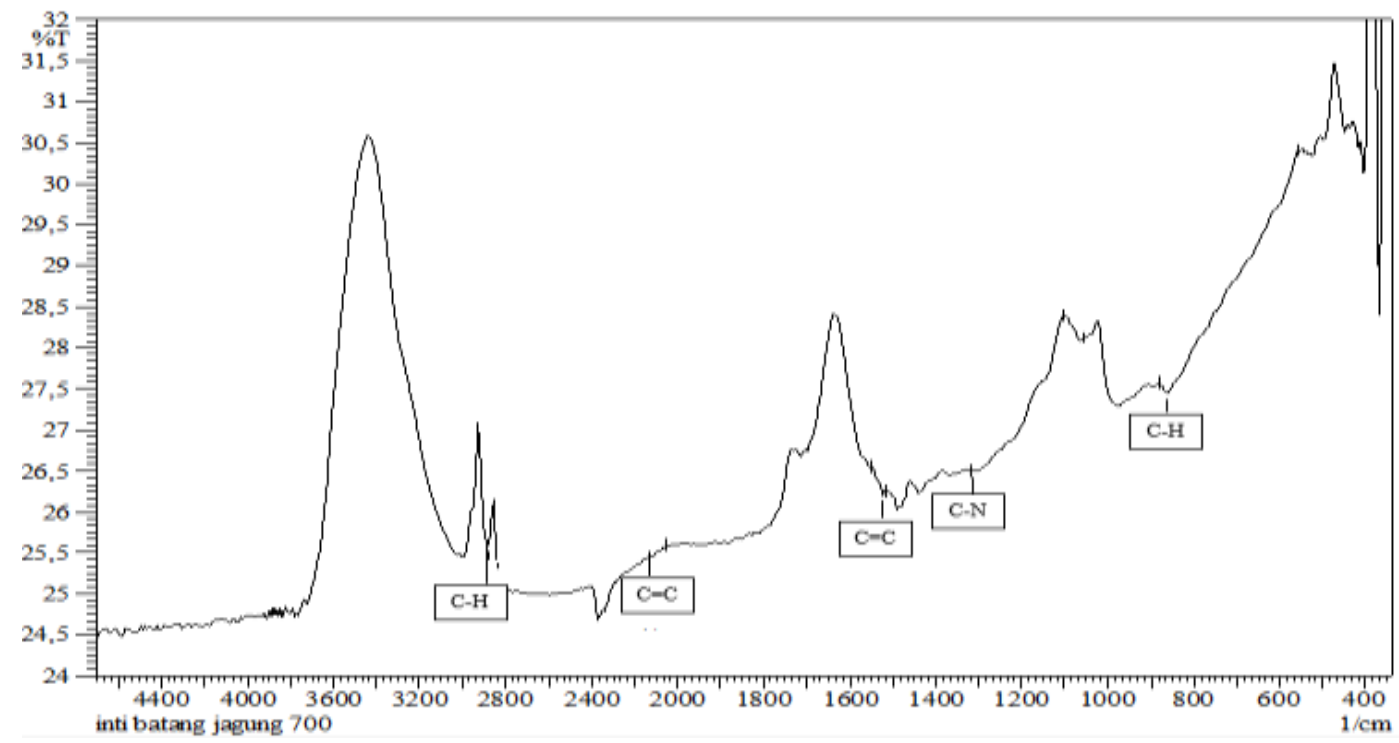

Figure 3. Carbon chain structure of CSC700.

The carbon chain structure test results showed a highly complex surface of activated carbon. The resulting carbon chain has a role in the formation of a double layer in supercapacitor cells. The functional group above is hydrophilic and has a role in acid and alkaline equilibrium in supercapacitor cells when contact occurs between the surface of carbon electrodes with $\mathrm{H}^{+}$or $\mathrm{OH}^{-}$ions.

\subsection{Electrochemical Properties of Supercapacitor Cells}

The electrochemical properties of supercapacitor cells were tested using Cyclic Voltammetry (CV). CV aimed to test the performance produced by supercapacitor cells. Data obtained from $\mathrm{CV}$ measurements were then used to calculate the specific capacitance of supercapacitor cells using Equation (1). The cell curve of supercapacitors based on the variations in the activation temperature with a scan rate of $1 \mathrm{mVs}^{-1}$ and a potential difference of $0-500 \mathrm{mV}$ can be seen in Figure 4.

The curve formed in Figure 4 resembles a rectangle. This is the ideal curve produced by the CV test in supercapacitor electrodes. The largest I-V curve area was produced by CSC700 carbon electrodes while the smallest I-V curve area was produced by CSC800. This result is influenced by the shape of the particles and the porosity of the samples. Furthermore, these results are in accordance with the data of the produced density. The charge and discharge process are also influenced by the pore conditions of the sample. 
The charge process is characterized by the upper curve while the discharge process is marked on the bottom curve. The measurement data of the current charge (Ic) and discharge (Id), and the calculation of Csp values are presented in Table 1. Specific capacitances produced at a scan rate of 1 mVs-1by CSC600, CSC700, and CSC800 samples were 89.5 Fg-1, 108.9 Fg-1, and 44.6 Fg-1, respectively. The magnitude of this specific capacitance is influenced by the Ic-Id curve size formed in the activated carbon samples.

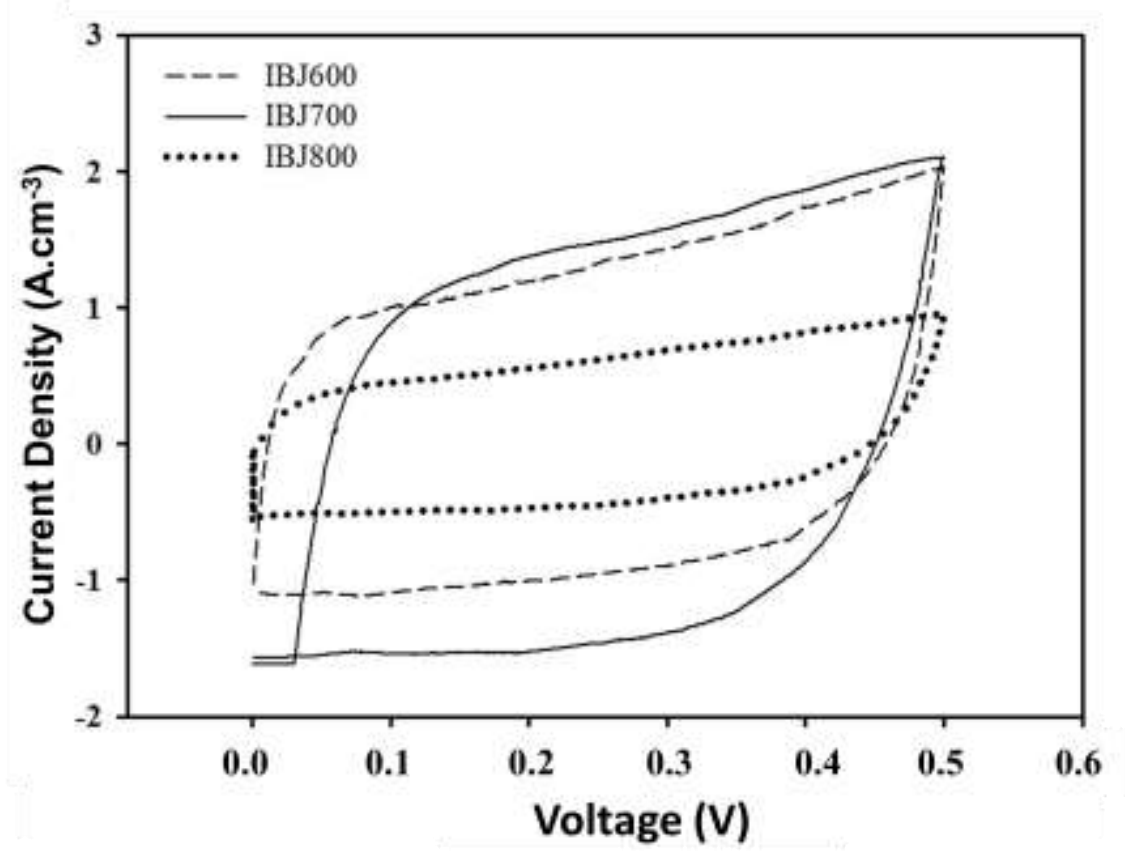

Figure 4. The CV curve of CSC carbon electrodes

Table 1. Data obtained from the CV test.

\begin{tabular}{cccccc}
\hline Sample Code & Mass $(\mathrm{g})$ & $\begin{array}{c}\mathrm{I}_{\mathrm{c}} \\
(\mathrm{A})\end{array}$ & $\begin{array}{c}\mathrm{I}_{\mathrm{d}} \\
(\mathrm{A})\end{array}$ & $\begin{array}{c}\mathrm{S} \\
\left(\mathrm{Vs}^{-1}\right)\end{array}$ & $\begin{array}{c}\mathrm{C}_{\mathrm{sp}} \\
\left(\mathrm{Fg}^{-1}\right)\end{array}$ \\
\hline IBJ600 & 0.0255 & 0.001329 & -0.000954 & 0.001 & 89.5 \\
IBJ700 & 0.0270 & 0.001479 & -0.001462 & 0.001 & 108.9 \\
IBJ800 & 0.0240 & 0.000619 & -0.000451 & 0.001 & 44.6 \\
\hline
\end{tabular}

The specific capacitance produced by CSC600 was quite high. The formation of pores is still relatively small at $600^{\circ} \mathrm{C}$. This is characterized by small changes in density before and after activation. However, in the activation at $700^{\circ} \mathrm{C}$, the specific capacitance increased. The increase in specific capacitance is due to a significant density decrease and more pores shown in the electron scanning microscope characterization. The formed pores help during the charge and discharge process so that electrolyte ions will diffuse well into the carbon matrix [17]. The results of pore formation produced the highest capacitance value for CSC700 carbon electrodes. In contrast, CSC800 had the lowest specific capacitance value. This happens because when the temperature increases, the formed pores damage some pores and close other pores, so the transport of ions into the carbon matrix is inhibited [15]. 


\section{Conclusion}

The fabrication and characterization of supercapacitor cell electrodes from CSC with various activation temperatures were conducted. Electrochemical measurements showed that CSC700 had a good capacitive performance by producing the highest capacitance value with 108.9 Fg-1. This result is also supported by the physical properties of supercapacitor electrodes. The lowest density was produced by CSC700 which had an effect on the amount of specific capacitance. The surface morphological characteristics showed that CSC700 pores were numerous and varied with sizes ranging from $0.882 \mu \mathrm{m}$ to $2.316 \mu \mathrm{m}$. The carbon chain structure of CSC700 also helps in the formation of a double layer in supercapacitor cells. In conclusion, $700^{\circ} \mathrm{C}$ is the optimum activation temperature for the preparation of supercapacitor from CSC carbon electrodes.

\section{Acknowledgment}

The authors would like to thank DP2M of High Directorate through Higher Education Leading Basic Research Project (PDUPT) with the title of "Potential Utilization of Urban Solid Waste as Supercapacitor Electrodes" in 2017.

\section{REFERENCES}

[1] X. Gao and et al, "Superior capacitive performance of active carbons derived from Enteromorpha prolifera," Electrochim. Acta, vol. 133, pp. 459-466, 2014.

[2] L. Sun, C. Tian, M. Li, X. Meng, L. Wang, R. Wang, J. Yin and H. Fu, "From coconut shell to porous graphene-like nanosheets for high-power supercapacitors," Journal of Materials Chemistry A, vol. 1, pp. 6462-6470, 2013.

[3] M. Biswal, A. Banerjee, M. Deo and S. Ogale, "From dead leaves to high energy density supercapacitors," Energy \& Environmental Science, vol. 6, pp. 1249-1259, 2013.

[4] X. L. Wu, T. Wen, H. L. Guo, S. B. Yang, X. K. Wang and A. W. Xu, "Biomass-derived sponge-like carbonaceous hydrogels and aerogels for supercapacitors," ACS Nano, vol. 7, pp. 3589-3597, 2013.

[5] X. Bai, X. H. Chen, D. S. Zhang, H. H. Song and Y. D. Yue, "Preparation and electrochemical properties of bamboo-based electrode materials for supercapacitor," Carbon Techniques, vol. 1, pp. 9-14, 2009.

[6] H. Jin, X. Wang, Z. Gu, J. D. Hoefelmeyer, K. Muthukumarappan and J. Julson, "Graphitized activated carbon based on big bluestem as an electrode for supercapacitors," RSC Adv., vol. 4, no. 27, p. 14136-14142, 2014.

[7] K. Sahay, "Supercapacitor Energy Storage System For Power Quality Improvement," $J$. Electr. Syst., vol. X, pp. 1-8, 2009.

[8] A. Burke, "Ultracapacitors: Why, how, and where is the technology," J. Power Sources, vol. 91, no. 1, pp. 37-50, 2000.

[9] G. Wang, L. Zhang and J. Zhang, "A review of electrode materials for electrochemical supercapacitors," Chemical Society Reviews, vol. 41, no. 2, pp. 797-828, 2012.

[10] X. Gu, X. Liu, N. T. Van Dam, P. R. Hof and J. Fan, "Cognition-emotion integration in the anterior insular cortex," Cereb. Cortex, vol. 23, no. 1, pp. 20-27, 2013.

[11] L. K. Ong, A. Kurniawan, A. C. Suwandi, C. X. Lin, X. S. Zhao and S. Ismadji, "A facile 
and green preparation of durian shell-derived carbon electrodes for electrochemical doublelayer capacitors," Prog. Nat. Sci. Mater. Int., vol. 22, no. 6, pp. 624-630, 2012.

[12] S. Tang, Y. Chen, R. Xie, W. Jiang and Y. Jiang, "Preparation of activated carbon from corn cob and its adsorption behavior on Cr(VI) removal," Water Sci. Technol., vol. 73, no. 11, pp. 2654-2661, 2016.

[13] M. Khodaie, N. Ghasemi, B. Moradi and M. Rahimi, "Removal of methylene blue from wastewater by adsorption onto znclactivated corn husk carbon equilibrium studies," $J$. Chem., 2013.

[14] Y. Zhang, A. E. Ghaly and B. Li, "Physical properties of corn residues," Am. J. Biochem. Biotechnol., vol. 8, no. 2, pp. 44-53, 2012.

[15] R. Satish, A. Vanchiappan, C. L. Wong, K. W. Ng and M. Srinivasan, "Macroporous carbon from human hair: A journey towards the fabrication of high energy Li-ion capacitors," Electrochim. Acta, vol. 182, pp. 474-481, 2015.

[16] M. Deraman, S. K. Saad, M. M. Ishak, Awitdrus, E. Taer, I. Talib, R. Omar and Jumali, "Carbon/carbon nanotubes (CNTs) composites from green pellets contain CNTs and selfadhesive carbon grains from fibres of oil palm empty fruit bunch," The Third Nanoscience and Nanotechnology Symposium, pp. 179-186, 2010.

[17] Y. Cao and et al, "Hierarchical porous activated carbon for supercapacitor derived from corn stalk core by potassium hydroxide activation," Electrochim. Acta, vol. 212, pp. 839$847,2016$.

[18] J. Barkauskas and M. Dervinyte, "An investigation of the functional groups on the surface of activated carbons," J. Serbian Chem. Soc., vol. 69, no. 5, pp. 363-375, 2004.

[19] H. Demiral and I. Demiral, "Surface properties of activated carbon prepared from wastes," Surface and Interface Analysis, vol. 40, no. 3-4, pp. 612-615, 2008.

[20] S. Pongpiacha, "FTIR Spectra of Organic Functional Group Compositions in PM2.5 Collected at Chiang-Mai City, Thailand during the Haze Episode in March 2012," J. Appl. Sci., vol. 14, no. 22, pp. 2967-2977, 2014. 